\title{
Low-Profile Broadband and Dual-Frequency Two-Strip Planar Monopole Antennas
}

\author{
B. Pan*, R. L. Li, J. Papapolymerou, J. Laskar, and M. M. Tentzeris \\ School of Electrical and Computer Engineering \\ Georgia Institute of Technology, Atlanta, GA 30332-0250, USA
}

\begin{abstract}
A novel type of low-profile broadband and dual-frequency monopole antennas is developed for wireless applications. The broadband monopole consists of an S-strip and a folded T-strip which are separately printed on the two sides of a thin planar substrate. No via process is involved in the fabrication. The two-strip planar monopole can achieve a bandwidth (VSWR $<2$ ) of $\sim 35 \%$ with a height of $0.056 \lambda_{0}$. The dual-frequency operation of the broadband monopole antenna is realized by adding a short T-strip to the S-strip and a couple of inverted-L strips to the folded T-strip. The dual-frequency monopole can accomplish a bandwidth of $\sim 40 \%$ at a lower-frequency band and $\sim 10 \%$ at a higher-frequency with a total height of $0.08 \lambda_{0}$.
\end{abstract}

\section{INTRODUCTION}

For applications in a portable wireless communication device, such as a mobile phone handset or a notebook computer, the antenna with a low-profile planar structure is essential for low-cost manufacture and easy integration with a printed circuit broad (PCB). On the other hand, the requirement for a dual-frequency operation is becoming a common sense in order to accommodate multi-functional services, such as voice, video, and data transmissions. To cover the DCS-1800, PCS-1900, IMT-2000/UMTS, the 2.4 GHz ISM band, and the 5.8-GHz UNII band, it needs a bandwidth of $\sim 40 \%$ at the lowerfrequency band (around $2 \mathrm{GHz}$ ) and a bandwidth of $\sim 10 \%$ at the higher-frequency band.

Monopole antenna is attractive for wireless applications due to its simple structure and omni-directional radiation pattern. However, a straight monopole usually has a height of larger than $\sim 0.15 \lambda_{0}$ [1], [2]. A simple way for reducing the antenna height is to bend or fold the straight monopole into some type of low-profile configuration, such as an inverted L or an inverted $\mathrm{F}$ [3], a double $\mathrm{S}$ or a double $\mathrm{T}$ [4], [5], or a meandered shape [6]. Unfortunately, a bent/folded monopole usually corresponds to a lower impedance bandwidth (typically $<10 \%$ for a VSWR $<2$ ), particularly, at the lower-frequency band of a dual-frequency operation. In general, it is more difficult to achieve a broad bandwidth at a lower frequency band than at a higher-frequency band due to the electrically smaller antenna size at a lower frequency. In recent years, a lot of efforts have been made to increase the impedance bandwidth while keeping a low antenna profile [7]. But most of techniques for bandwidth enhancement involve shorting metal walls and require a considerable antenna thickness $\left(>0.02 \lambda_{0}\right)$, not suitable for a fully photolithographic fabrication process. It has been found in [8] that electromagnetic coupling and two-strip configuration are two effective methods for increasing the bandwidth of a compact antenna structure. These methods have been demonstrated to be effective for a few threedimensional structures. In this paper, we combine the electromagnetic coupling and the two-strip configuration into a monopole structure folded on a very thin planar substrate (thickness $<0.002 \lambda_{0}$ ) for achieving a broadband operation. The dual-frequency operation is realized by adding some parasitic elements into the broadband structure. There is no shorting via involved in the antenna structure.

\section{BROADBAND OPERATION}

The geometry of a low-profile broadband two-strip planar monopole antenna is illustrated in Fig. 1. This antenna is designed at the $2 \mathrm{GHz}$ band based on an RT/Duroid 5880 planar substrate which has a dielectric constant of $\varepsilon_{\mathrm{r}}=2.2$ and a thickness of $\mathrm{t}=10$ mils $(0.254$ 
$\mathrm{mm}$ ). The antenna is printed on both sides (i.e., the front side and the backside) of the substrate. On the front side, there is a T-strip whose lower section is folded and extended to a $50-\Omega$ microstrip feedline. On the backside of the substrate, there is an S-strip which is terminated at a ground plane. The upper section of the T-strip is fitted into the area surrounded by the upper section of the S-strip. The height $\left(\mathrm{H}_{\mathrm{T}}\right)$ and width $\left(\mathrm{W}_{\mathrm{T}}\right)$ of the Tstrip are slightly shorter than those (i.e., $\mathrm{H}$ and $\mathrm{W}$ ) of the S-strip. To alleviate the skin effect, the crossbar of the T-strip is divided into some narrow strips whose width and separation are equal to the width $\left(\mathrm{w}_{\mathrm{s}}\right)$ of the $\mathrm{S}$-strip, which is approximately equal to the width $\left(\mathrm{w}_{\mathrm{f}}\right)$ of the $50-\Omega$ microstrip feedline. The folded lower section of the T-strip on the front side overlaps with the lower section of the S-strip on the backside, forming a twostrip line. There is no directly electrical connection (e.g., by a shorting via) between the front side and the backside. A prototype of the low-profile broadband antenna is shown in Fig. 2. The total height of the antenna is $H=8.4 \mathrm{~mm}\left(0.056 \lambda_{0}, \lambda_{0}\right.$ is the free-space wavelength at $2 \mathrm{GHz})$ and the width $\mathrm{W}=18 \mathrm{~mm}\left(0.12 \lambda_{0}\right)$. Other geometrical parameters are attached in the caption of Fig. 1.

To demonstrate the performance of the low-profile two-strip monopole, the antenna structure was simulated using MicroStripes 6.5 and HFSS 9.1. Fig. 3 shows the return loss of the low-profile two-strip monopole. The bandwidth for VSWR $<2$ is found to be $\sim 35 \%$. The measured result confirms the broadband performance. The effect of the monopole width (W) on the operating frequency is displayed in Fig. 4. As expected, the operating frequency shifts up when $\mathrm{W}$ decreases; therefore, the width $\mathrm{W}$ can be used for tuning the operating frequency to a specified frequency band. The low-profile two-strip antenna has an omni-directional pattern in the $\mathrm{x}-\mathrm{y}$ plane with a peak gain of $\sim 2 \mathrm{dBi}$.

\section{DUAL-FREQUENCY OPERATION}

In order to cover the $5.8 \mathrm{GHz}$ UNII band for WLAN applications (e.g., IEEE 802.11a), three parasitic elements are added to the two-strip monopole for achieving a dualfrequency operation. Fig. 5 shows the configuration of the dual-frequency monopole antenna. A short T-strip is attached to the lower section of the S-strip while a couple of inverted-L strips are branched from the lower section of the T-strip. The dominant radiating element in the $5.8 \mathrm{GHz}$ band is the short T-strip which is electromagnetically coupled with the inverted-L strips. The addition of the parasitic elements can increase the level of return loss in the $2 \mathrm{GHz}$ band. To alleviate this effect, the height $\left(\mathrm{H}_{\mathrm{T} 2}\right)$ of the short T-strip should keep as low as possible and it is necessary to keep a certain separation distance (i.e., D) between the upper and lower parts of the S-strip/T-strip. Numerical simulation shows that $\mathrm{H}_{\mathrm{T} 2}$ should be less than $1.5 \mathrm{~mm}$ while $\mathrm{D}$ should be more than $4 \mathrm{~mm}$ to keep the return loss in the $2 \mathrm{GHz}$ band is lower than $-10 \mathrm{~dB}$. The level of return loss in the $5.8 \mathrm{GHz}$ band can be optimized by adjusting the widths $\left(\mathrm{W}_{\mathrm{L} 1}\right.$ and $\left.\mathrm{W}_{\mathrm{L} 2}\right)$ and the height $\left(\mathrm{H}_{\mathrm{L}}\right)$ of the inverted- $\mathrm{L}$ strips. The optimal values for $\mathrm{W}_{\mathrm{L} 1}, \mathrm{~W}_{\mathrm{L} 2}$, and $\mathrm{H}_{\mathrm{L}}$ are found to be $6.0 \mathrm{~mm}, 6.0 \mathrm{~mm}$, and $0.75 \mathrm{~mm}$, respectively. The total height $(\mathrm{H})$ of the dualfrequency monopole is $12 \mathrm{~mm}\left(0.08 \lambda_{0}\right)$. A prototype of the dual-frequency antenna is shown in Fig. 6. The simulated and measured results for return loss are compared in Fig. 7. The bandwidth in the $5.8 \mathrm{GHz}$ band is found to be $\sim 10 \%$ while the bandwidth in the $2 \mathrm{GHz}$ band remains $\sim 40 \%$.

\section{CONCLUSION}

The profile of a monopole antenna can be lowered by making use of an S-strip and a folded T-strip. By combining the S-strip and the T-strip into a planer substrate, the bandwidth of the two-strip monopole is significantly increased. A broadband dualfrequency operation is realized by adding more parasitic elements into the two-strip monopole structure. A bandwidth of $\sim 35 \%$ is achieved for the two-strip monopole with a 
height of $0.056 \lambda_{0}$ while the dual-frequency antenna realizes a bandwidth of $\sim 40 \%$ in the 2 $\mathrm{GHz}$ band and $\sim 10 \%$ in the $5.8 \mathrm{GHz}$ band. The low-profile two-strip monopole antennas are easy to fabricate with possible integration with RF front-end circuits. This type of broadband and dual-frequency antennas may find applications in $2 \mathrm{G} / 3 \mathrm{G}$ cellular phones and WLAN devices.

\section{Acknowledgement}

The authors wish to acknowledge the support of Georgia Electronic Design Center and the NSF Packaging Research Center.

\section{References}

[1] H.-D. Chen and H.-T. Chen, "A CPW-fed dual-frequency monopole antenna," IEEE Trans. Antennas Propagat., vol. 52, no. 4, pp. 978-982, April 2004.

[2] W.-C. Liu, "Design of multiband CPW-fed monopole antenna using a particle swarm optimization approach," IEEE Trans. Antennas Propagat., vol. 53, no. 10, pp. 3273-3279, Oct. 2005.

[3] H. Nakano, Y. Sato, H. Mimak, and J. Yamauchi, "An Inverted FL antenna for dual-frequency operation," IEEE Trans. Antennas Propagat., vol. 53, no. 8, pp. 2417-2421, Aug. 2005.

[4] W.-C. Liu, W.-R. Chen, and C.-M. Wu, "Printed double S-shaped monopole antenna for wideband and multiband operation of wireless communications," IEE Proc.-Microw. Antennas Propag. vo1. 151, no. 6, pp. 473-476, Dec 2004.

[5] Y.-L. Kuo and K.-L. Wong, "Printed double-T monopole antenna for 2.4/5.2 GHz dual-band WLAN operations," IEEE Trans. Antennas Propagat., vol. 51, no. 9, pp. 2187-2192, Sept. 2003.

[6] N. T. Pham, G.-A. Lee, and F. D. Flaviis, "Minimized dual-band coupled line meander antenna for system-in-a-package applications," IEEE AP-S International Symposium, vol. 2, pp. 14511454, June 2004.

[7] L. Zaid, G. Kossiavas, J.-Y. Dauvignac, J. Cazajous, and A. Papiernik, "Dual-Frequency and broad-band antennas with stacked quarter wavelength elements," IEEE Trans. Antennas Propagat., vol. 47, no. 4, pp. 654-660, April 1999.

[8] H. D. Foltz, J. S. Mclean, and G. Crook, "Disk-loaded monopoles with parallel strip elements," IEEE Trans. Antennas Propagat., vol. 44, no. 5, pp. 672-676, May 1996.

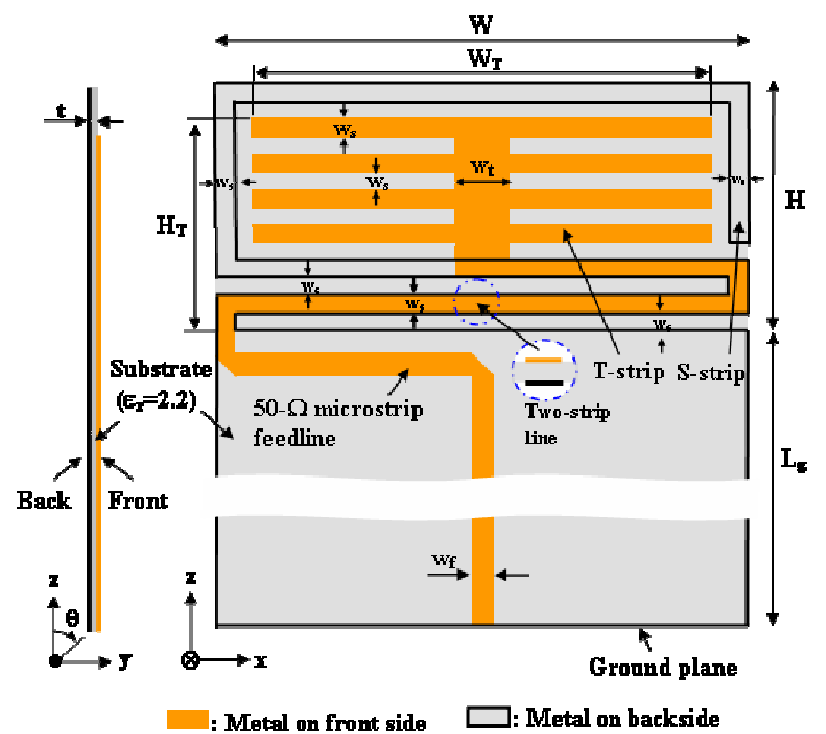

Fig. 1. Geometry of a broadband two-strip planar monopole antenna, which includes an S-strip on the front side and a Tstrip on the backside of a planar substrate. [Geometrical parameters: $\mathrm{H}=8.4 \mathrm{~mm}\left(0.056 \lambda_{0}\right), \mathrm{W}=18 \mathrm{~mm}\left(0.12 \lambda_{0}\right), \mathrm{H}_{\mathrm{T}}=7.2$ $\mathrm{mm}, \mathrm{W}_{\mathrm{T}}=15.6 \mathrm{~mm}, \mathrm{~W}_{\mathrm{t}}=1.8 \mathrm{~mm}, \mathrm{w}_{\mathrm{f}}=0.76 \mathrm{~mm}, \mathrm{t}=0.254 \mathrm{~mm}$, and $\mathrm{L}_{\mathrm{g}}=20 \mathrm{~mm}$.]

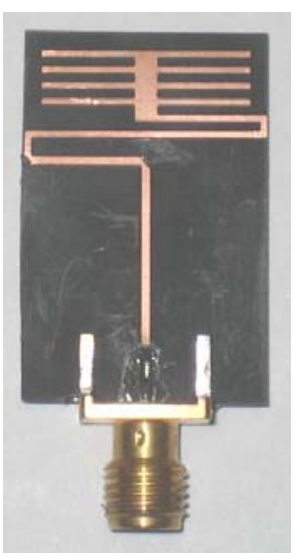

(a) Front view

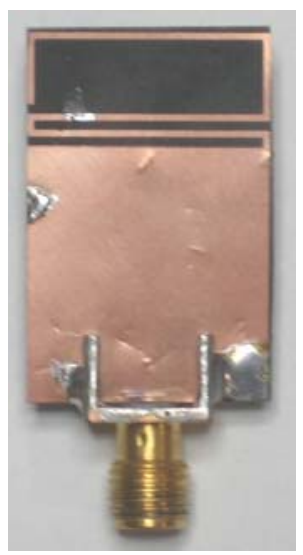

(b) Back view
Fig. 2. Photo of a prototype of the lowprofile broadband two-strip monopole antenna. 


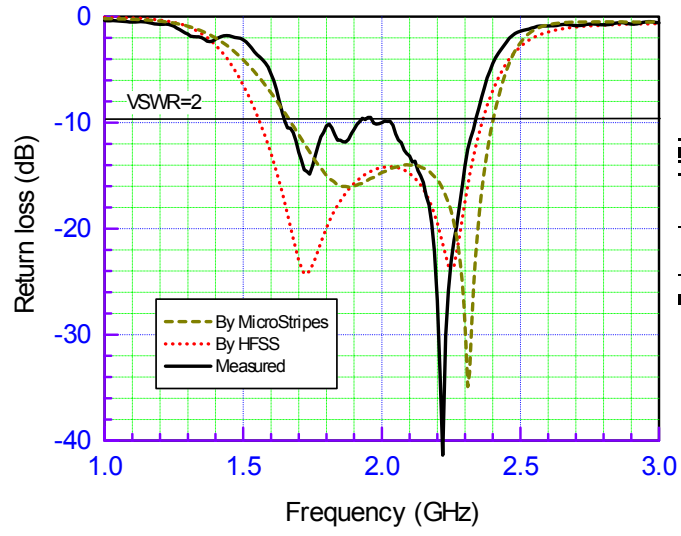

Fig. 3. Measured and simulated results for return loss of the low profile broadband two-strip monopole antenna.

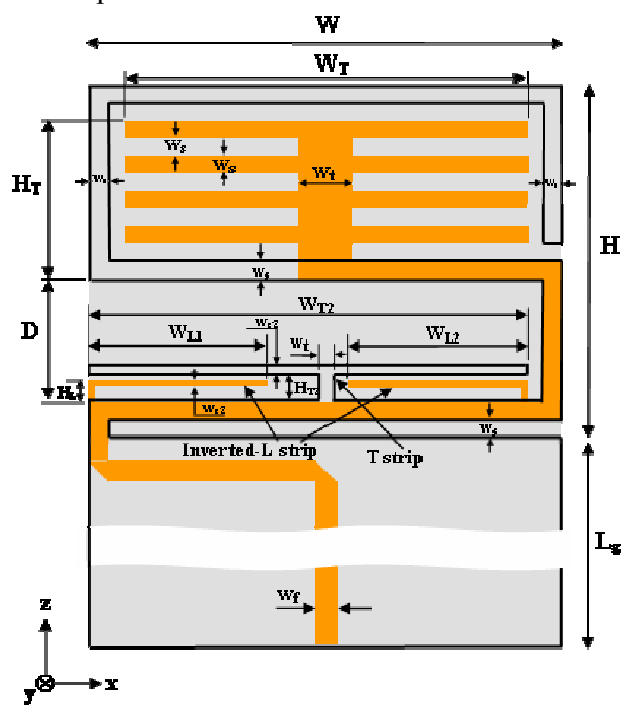

Fig. 5. Configuration of a broadband and dual-frequency two-strip monopole antenna. [Geometrical parameters: $\mathrm{H}=12$ $\mathrm{mm}\left(0.08 \lambda_{0}\right), \mathrm{W}=16 \mathrm{~mm}\left(\sim 0.11 \lambda_{0}\right), \mathrm{H}_{\mathrm{T}}=10.8 \mathrm{~mm}, \mathrm{~W}_{\mathrm{T}}=13.9$ $\mathrm{mm}, \mathrm{D}=4.2 \mathrm{~mm}, \mathrm{~W}_{\mathrm{t}}=1.8 \mathrm{~mm}, \mathrm{H}_{\mathrm{T} 2}=1.0 \mathrm{~mm}, \mathrm{~W}_{\mathrm{T} 2}=14.8 \mathrm{~mm}$, $\mathrm{H}_{\mathrm{L}}=0.75 \mathrm{~mm}, \mathrm{~W}_{\mathrm{L} 1}=\mathrm{W}_{\mathrm{L} 2}=6.0 \mathrm{~mm}, \mathrm{w}_{\mathrm{s}}=0.6 \mathrm{~mm}, \mathrm{w}_{\mathrm{s} 2}=0.25 \mathrm{~mm}$, $\mathrm{w}_{\mathrm{t}}=0.5 \mathrm{~mm}, \mathrm{w}_{\mathrm{f}}=0.76 \mathrm{~mm}, \mathrm{t}=0.254 \mathrm{~mm}$, and $\mathrm{L}_{\mathrm{g}}=20 \mathrm{~mm}$.]

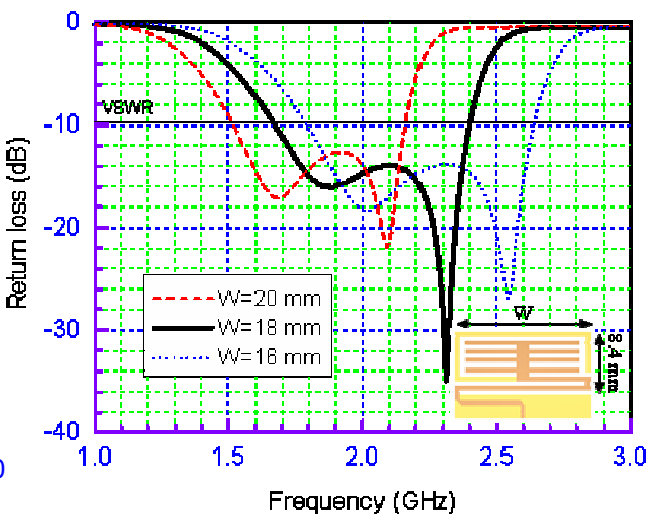

Fig. 4. Effect of the width (W) on the operating frequency of a two-strip monopole antenna.

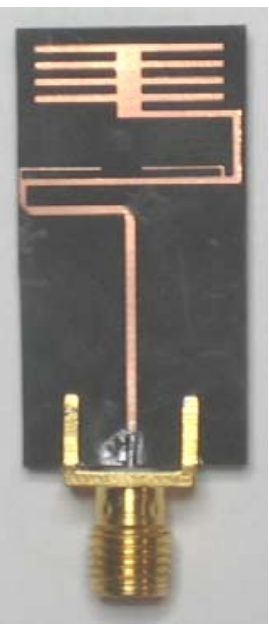

(a) Front view

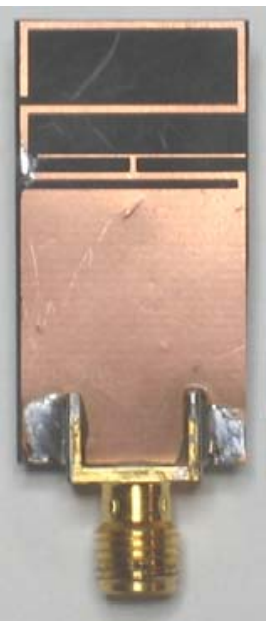

(b) Back view
Fig. 6. Photo of a prototype of the broadband and dual-frequency two-strip monopole antenna.

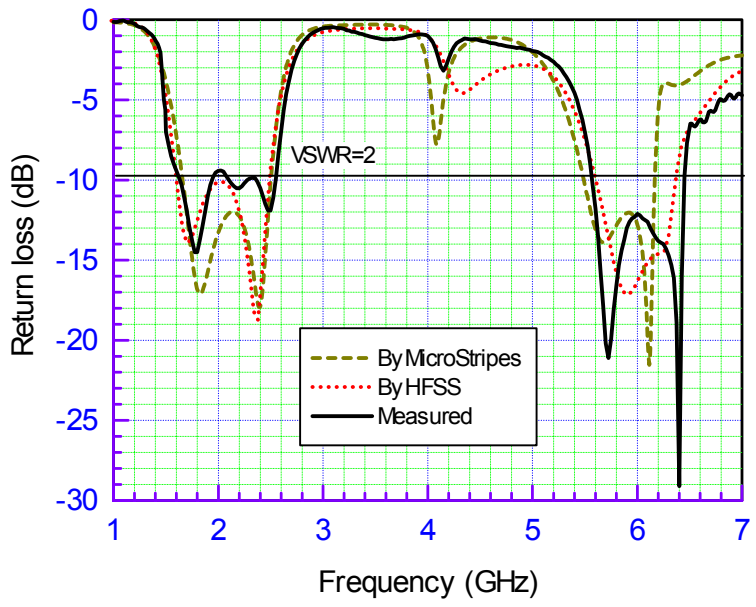

Fig. 7. Measured and simulated results for return loss of the dual-frequency two-strip antenna. 